\title{
A HISTÓRIA COMO JOGO: CONTRIBUIÇÕES DE MICHEL FOUCAULT PARA O ENSINO DA HISTÓRIA
}

\author{
GAME AS HISTORY: CONTRIBUTIONS OF MICHEL FOUCAULT TO DO \\ HISTORIOGRAPHY
}

\author{
Luciano Rocha Pinto ${ }^{1}$
}

\begin{abstract}
Resumo: O presente trabalho busca evidenciar uma "Teorien", um modo de ver norteador a partir da abordagem teórica e metodológica proposta por Michel Foucault. Acusado de não possuir um método, o filósofo-historiador amplia a perspectiva ou o olhar dos historiadores com outro modo de ver, pensar e construir a história. Nunca foi óbvio ou transparente, nem elaborou esquemas teóricos de fácil medição do que seria a realidade. Foi criticado e, por vezes, mal compreendido, por apresentar um olhar diferenciado e feroz contra as ideias de continuidade, totalidade, sujeitos fundadores, origens nobres e abordagens teleológicas. Suas noções de descontinuidade e poder relacional instauram outro olhar sobre a história, que deve ser percebida como um jogo.
\end{abstract}

Palavras-chave: História. Teoria. Poder. Michel Foucault. Ensino de História

\begin{abstract}
This paper tries to reveal a "Teorien", a way of guiding the view from the theoretical and methodological approach proposed by Michel Foucault. Accused of not having amethod, the philosopher-historian will broaden the perspective of historians or the lookof anoyher way of seeing, thinking and build the story. It was never obvious or transparent, not elaborated theoretical frameworks easy to measure than is the reality. He was criticized and sometimes misunderstood, because it presents a different lookand fierce against the ideas of continuity, all subject founding noble origins and teleological approaches. The notions of discontinuity and relational power introduce another look at history, it must be perceived as a game.
\end{abstract}

Keywords: History. Theory. Power. Michel Foucault

${ }^{1}$ Pesquisador do Laboratório de Estudos das Diferenças e Desigualdades Sociais (LEDDESUERJ). Doutorando do Programa de Pós-Graduação em História Política da Universidade do Estado do Rio de Janeiro (PPG-História-UERJ). 
Não basta aprender o que tem de se dizer em todos os casos sobre um objeto, mas também como devemos falar dele. Temos sempre de começar por aprender 0 método de o abordar (WITTGENSTEIN, 1987, p. 431).

\section{Introdução}

O presente trabalho se propõe discutir as contribuições de Michel Foucault para o ensino da história. Está dividido em três partes. As duas primeiras são um exercício de reflexão a respeito da percepção de Michel Foucault sobre o sentido da História e sua contribuição original como a primazia da descontinuidade (parte 1), onde levanto suas críticas ao "estatuto do real", à noção de verdade e documento; e realço seu método de trabalho arqueogenealógico ${ }^{2}$ como uma proposta para o ensino da história. Na parte 2 abordo o surgimento de uma nova concepção acerca da anatomia do poder. Opondo-se ao modelo do Leviatã, concepção contratualista do poder, e ao modelo marxista economicista, que entendem o poder como coisa, ou posse. Foucault se apropria da "hipótese Nictzsche", ou seja, de uma noção de poder concebido como luta. O poder é relacional, todos, em algum sentido ou direção, o exercem ao mesmo tempo em que sofrem seus efeitos. Não mais o Estado como centro irradiador do poder, mas o poder enquanto rede. Interessa o "como" do poder, os modos de sujeição e as técnicas de disciplina e normalização.

Na última parte, História como jogo, procuro amarrar as questões levantadas e mostrar o modo como Foucault compreende as relações humanas. A palavra "jogo" ilustra seu olhar acerca do mundo e da História. São as próprias praticas humanas, na maior parte das vezes, conflituosas

2 "Arqueologia e genealogia se apoiam sobre um pressuposto comum: escrever a história sem referir a análise à instância fundadora do sujeito (...) [Trata-se de] analisar o saber em termos de estratégia e táticas de poder. Nesse sentido, trata-se de situar o saber no âmbito das lutas" (CASTRO, 2009, p. 185).

"O uso da palavra arqueologia indica que se trata de um procedimento de escavar verticalmente as camadas descontínuas de discursos já pronunciados (...) a fim de trazer à luz fragmentos de ideias, conceitos, discursos talvez já esquecidos" (VEIGA-NETO, 2011, p.45).

"A genealogia trata das relações de poder" (PEY, BACCA, SÁ, 2004, p. 21). 
que fazem o acontecer da História, não havendo um sentido a priori, nem uma essência teleológica, original, racional e metafísica que guie o movimento do homem no tempo. A História é o acontecimento, marcado pelas táticas e estratégias dos processos de hierarquização, próprias de um jogo. Assim, não faz sentido ensinar/estudar uma História simplesmente centrada nas ações governamentais, políticas e econômicas. A história deve fazer emergir os diversos núcleos de poder, o homem simples e o cotidiano; assim como suas ressignificações. Foucault propõe outra abordagem da História. Na verdade, ele faz emergir outro modo de pensar a História. Parodiando o que bem disse Wittgenstein, na epígrafe que abre este trabalho, não é suficiente falar ou descrever os objetos, "temos de começar por aprender o método de o abordar" (WITTGENSTEIN, 1987, p. 431). Segue, então, as contribuições/sugestões metodológicas de Foucault, como este outro jeito de pensar e de olhar, um outro modo de abordagem da história.

\section{(1) Primazia da Descontinuidade.}

Há dezenas de anos que a atenção dos historiadores se voltou, de preferência, para os longos períodos, como se, sob as peripécias políticas e seus episódios, eles se dispusessem a revelar os equilíbrios estáveis e difíceis de serem rompidos (...) As velhas questões de análise tradicional são substituídas, de agora em diante, por interrogações de outro tipo. (FOUCAULT, 2007, pp. 3-4).

Foucault não critica a História, mas um determinado modo de pensála e ensiná-la. Ao longo de "A Arqueologia do Saber" é possível perceber uma defesa declarada à História visando libertá-la, do que denominou, de noções e procedimentos envelhecidos (continuidade, sujeito fundador, totalidade, origens nobres e abordagens teleológicas) fazendo uma série de críticas àquele modo de pensar uma história contínua e globalizante.

A historiografia tradicional é aquela iniciada em meados do século XIX e que se estendeu até o início do século XX, a chamada escola metódica, que estabeleceu um discurso cientificista aos historiadores se distanciando 
do discurso literário. Para ela a História era contínua, linear e feita de grandes nomes e eventos políticos. Nação, civilização, revolução, eram temas da História. Objetivava-se recuperar o passado da nação e de seus líderes. A História aparecia como um conhecimento globalmente organizado num continuum harmonioso (CRUZ, 2001, p. 67). Como indica seu nome grego, a História era a narrativa e suas personagens testemunhavam os grandes feitos do passado. Não havia lugar para a singularidade e para o descontínuo. Se era singular e descontínuo não poderia ser histórico, pois, a História era uma grande continuidade de fotos movidos por causas e efeitos constantes. Havia harmonia e equilíbrio. Havia "cientificidade".

É este "estatuto do real" que Foucault critica em sua ilusão de recompor a realidade, como se fosse possível ao pesquisador descobrir o que de fato aconteceu. Partindo do pressuposto que a realidade é uma construção discursiva passa-se a questionar um verismo que por muito tempo marcou o fazer histórico, fruto da ilusão cientificista de dominar a realidade. "Saber o que aconteceu" definiu por muito tempo o procedimento do historiador. A materialização dos fatos históricos, como entes ordenáveis e preexistentes, dava segurança e cientificidade à História. Como as ciências naturais, caberia à História descobrir a lógica da realidade, suas leis e, assim, ordená-la.

A História não é uma fabricação artesanal de corte e costura dos acontecimentos. Os fatos não são retalhos dispersos esperando para serem ordenados na colcha do tempo que a todos cobre e lhes oferece lugares específicos e cores previamente acertadas. Uma segunda crítica surge, então, da noção documento. A preocupação documental, fundamentalmente de cunho oficial, era uma característica da escola metódica. Os arquivos oficiais pareciam incontestes, verídicos. Para fugir da narrativa romântica, buscava-se fidelidade ao documento. Narrava-se os fatos "tais como aconteceram" segundo a documentação oficial do Estado.

A história nova é estritamente metódica. Em nome de um racionalismo total (...) prega unicamente o estudo das fontes escritas: coleta dos documentos (heurística), crítica externa (data, autor, origem...), crítica interna (hermenêutica), resumo crítico, síntese e colocação em perspectiva dos dados. 
O método rompe com o aproximativo que dominava freqüentemente uma historiografia feita por inúmeros historiadores mais de coração do que de formação. (TÉTART, 2000, p.109).

Em Foucault a História não escreve a si mesma, não tem sentido por si só, nem os documentos falam por si. Ela não é um quebra-cabeça que possui uma ordem previamente estabelecida pela realidade, de forma que caiba, a quem se debruça sobre ela, apenas descobrir suas conexões. Não se trata de reconstruir o que os homens fizeram ou pensaram pela simples transcrição documental e arrumação dos fatos cronológicos. Foucault propõe uma História em que não há heurística, pois não existe nenhuma verdade oculta por ser descoberta. Não há busca "da verdade". Não há uma verdade há ser ensinada. Mais do que fatos verídicos o estudo da História deve se concentrar na produção da verdade, na trama das diversas "verdades" que desejam se impor no cotidiano conflitivo e caótico. Esso outro olhar sugere uma nova abordagem do documento.

...A história mudou sua posição acerca do documento: ela considera como sua tarefa primordial, não interpretá-lo, não determinar se diz a verdade nem qual é seu valor expressivo, mas sim trabalhá-lo no interior e elaborá-lo: ela o organiza, recorta e distribui, ordena e reparte em níveis, estabelece séries, distingue o que é pertinente do que não é, identifica elementos, define unidades, descreve relações. O documento, pois, não é mais para a história, essa matéria inerte através da qual ela tenta reconstruir o que os homens fizeram ou disseram, o que é passado e o que deixa apenas rastros: ela procura definir, no próprio tecido documental, unidades, conjuntos, séries, relações. (FOUCAULT, 2007, p. 7).

O documento passa a ser visto dentro de outra lógica. Não mais aquela fonte inerte de informações, com uma lógica própria emergindo dos fatos descritos, mas uma produção histórica que trás a lógica de seus produtores. O documento passa a ser visto, em si mesmo, como um fato histórico. Um acontecimento que traz em si mesmo as múltiplas relações de poder que o produziram. Não interessa ser fiel a ele, reproduzi-lo, mas, compreender como que as informações que traz foram possíveis. "A História, embora possa parecer, às vezes, homogênea, contínua, habitada pela semelhança, pela repetição, pelo mesmo, é trabalhada por dentro pela 
diferença, pela heterogeneidade, pela descontinuidade..." (ALBUQUERQUE JR, 2007, p. 31). É preciso dar uma inteligibilidade aos documentos, arrumá-los, dar uma lógica à sua materialidade, inserir uma coerência aos fatos dispersos. Nada que chegou até nós foi arquivado inocentemente. As evidências são fabricações. O documento é, em si, um acontecimento histórico. A acontecimentalização é seu método de trabalho. Ao fazer surgir a singularidade, como um procedimento de análise histórica, busca-se suprimir os encadeamentos naturais e teleológicos e fazer emergir os jogos de poder, as estratégias de dominação e a construção da realidade em seu caráter discursivo.

Foucault traz de Nietzsche a noção de história efetiva, que faz ressurgir o acontecimento em sua singularidade. Faz vir à tona as relações que possibilitaram aquele acontecimento. É um método de análise das condições históricas (do à priori histórico) que fizeram que em um dado momento determinado acontecimento (discursivo ou não) tivesse sido efetivamente possível. Ele não entende o fato como algo dado, mas produzido. Não toma o acontecimento como realidade, mas se pergunta como foi possível. Desrealiza-o na relação de força em que foi produzido. Não faz a história dos sujeitos e dos objetos, mas das possibilidades de materialização daqueles que aparecem naturalizados. Assim, busca problematizar (desnaturalizar) as experiências e os discursos. Ambos são vistos como acontecimentos que estão na ordem do poder. O próprio sujeito e as experiências são desnaturalizados e vistos como uma produção.

A experiência não é pura empiria, pois esta depende do modo como é concebida. Como o "real", por sua vez, é o insuportável e o caótico, o discurso reinventa a realidade, Ihe dá sentido, uma vez que em si mesma é vazia. "Nenhum ser humano suporta o real se não trabalhá-lo simbolicamente, se não aplacar sua estranheza através da dotação de sentido e significado...". (ALBUQUERQUE JR, 2007, p. 27). Relações, saberes e poderes moldam nosso modo de ser, ver, pensar, agir e interagir. Cada época histórica tem seu jeito particular de produzir sujeitos e reinventar a homem. O "como" experimentamos a realidade é uma produção. Os indivíduos são sujeitos históricos e historicizáveis. Ser 
brasileiro no início do século XXI não é o mesmo que sê-lo durante o Império. Temos a consciência possível de nosso tempo e lugar. Somos tanto sujeitos da história como objetos dela. Somos o resultado de relações múltiplas, de dotações de sentido, de saberes e poderes que produzem o simbólico, o cultural, as relações, os conflitos e as alianças.

Foucault assim critica a noção de sujeito fundador e recusa a pesquisa das "origens". Mais, ele propõe um estudo do homem em sociedade e no tempo que leve em consideração sua possibilidade de materialização. Nesta perspectiva, uma "linha do tempo", por exemplo, é uma imprecisão e, a um só tempo, uma violência. Quais fatos são considerados dignos de entrarem naquela periodização? Quais personagens são merecedores de compor o rol dos homens cujos feitos devem ser lembrados? Ao fazer esta seleção, que nunca é ingênua, há diversas motivações acerca do que se quer não apenas lembrar, mas, também do que se quer fazer esquecer. A história contínua, com seus sujeitos heroicos, está marcada por relações de poder, de desejos de verdade, ou pelo menos, motivada por uma determinada verdade que deseja ser reproduzida e lembrada em detrimento de tantas outras. Afinal: quem é o herói? Herói pra quem? Seus feitos poderiam ser considerados justos em todos os tempos e lugares?

A história contínua é o correlato indispensável da função fundadora do sujeito (...) Fazer da análise histórica o discurso do contínuo e fazer da consciência humana o sujeito originário de todo o devir e de toda prática são as duas faces de um mesmo sistema de pensamento. (FOUCAULT, 2007, p. 14).

O problema do sujeito é um dos temas centrais da obra de Foucault. A relação história/sujeito surge como domínio de seu trabalho, por ele mesmo descrito como uma história dos modos de subjetivação/objetivação do ser humano em nossa cultura. A história das práticas de subjetivação é uma ontologia de nós mesmos, da constituição histórica do que somos (CASTRO, 2009, p. 204). Não há sujeito fundador, pois, aquele que é considerado "fundador" é produto de sua época. Ademais ninguém estabelece nada sozinho. Somos animais sociais, relacionais. A questão não 
é saber quem escreveu o código criminal de 1830, por exemplo, mas o que permitiu que aquele código fosse escrito, que forças o produziram, quais os interesses em jogo. O indivíduo que o escreveu estava motivado por uma série de situações, pressionado por uma gama de forças, auxiliado por outros códigos, enfim, não há sujeito fundador como origem nobre. Mais interessante que promover nomes e coisas no ensino da História é mostrar como as coisas e os sujeitos foram inventados ao longo da História. O sujeito é uma invenção, assim como a realidade. Inventamos a História pelas nossas ações e representações assim como somos inventados pelas representações de realidade que nos precedem. O termo invenção...

...ganha destaque com o progressivo afastamento dos historiadores em relação às explicações que remetiam para o emprego de categorias trans-históricas, das abordagens metafísicas ou estruturais, que tendiam a enfatizar a permanência, a continuidade, e pressupunham a existência de uma essência, de um núcleo significativo da História, de determinadas relações ou processos como sendo determinantes de toda a variedade do acontecer histórico. (ALBUQUERQUE JR, 2007, p. 20).

O uso do termo "invenção" remete a uma abordagem que não toma os fatos como dados a priori, mas como construções históricas, enfatizando a descontinuidade, a singularidade e a ruptura. Há uma desnaturalização de objetos e sujeitos. Uma desmistificação na qual o historiador deixa de guiar um rastro metafísico ou originário e passa a debruçar-se no que os acontecimentos possuem de singular. A busca pela origem idealiza as coisas perfeitas, puras e essencializadas. "A origem está sempre antes da queda, antes do corpo, antes do mundo e do tempo". (FOUCAULT, 2003, p. 18). No começo o que existe é o conflito, a dúvida e a luta. Em Foucault as coisas deixam de ser evidentes e se tornam problemáticas, pois são, ao mesmo tempo, materialidade, relação social, jogos de força e produção de sentido. O discurso elaborado pelo historiador vai dar lógica à trama histórica. A noção de discurso, para Foucault, já é, em si mesmo, um acontecimento histórico. Todo discurso possui interesses, tem um lugar de produção, possui estratégia, vislumbra algo a conseguir ou chegar. Logo, o discurso é um instrumento de poder e é em si mesmo um acontecimento da 
ordem do poder que busca produzir efeitos. Não é a representação de um acontecimento, é, em si, um acontecimento.

Não procuro encontrar, por traz do discurso, alguma coisa que seria o poder e sua fonte (...) Eu parto do discurso tal como ele é! O tipo de análise que pratico não trata do problema do sujeito falante, mas examina as diferentes maneiras pelas quais o discurso desempenha um papel no interior do sistema estratégico em que o poder está implicado, e para o qual o poder funciona. Portanto, o poder não é nem fonte, nem origem do discurso. O poder é alguma coisa que opera através do discurso, já que o próprio discurso é um elemento em um dispositivo estratégico de relações de poder. (FOUCAULT, 2006, p. 253).

Produzimos verdades como produzimos riquezas, (FOUCAULT, 1999, p. 29) por isso Foucault se preocupa com a explicação da teia discursiva e das práticas que sustentam as verdades. O discurso não é imaterial, pois, é no âmbito da materialidade que ele se efetiva e produz efeitos. Seu lugar é o da relação, (FOUCAULT, 2004, p. 57) uma vez que cria o verdadeiro e o falso, o justo e o injusto, o legal e o ilegal, o normal e o anormal. 0 discurso "liga os indivíduos a certos tipos de enunciação e lhes proíbe, conseqüentemente, todos os outros (...) serve, em contrapartida, de certos tipos de enunciação para ligar indivíduos entre si e diferenciá-los, por isso mesmo, de todos os outros". (FOUCAULT, 2004, p. 43). Ao ver a produção do discurso como um acontecimento, Foucault ensina a desnaturalizar as verdades consagradas e fazer emergir os jogos de poder envolvidos naquilo que consideramos verdadeiro, justo, certo e normal.

Quando se fala em invenção da realidade e dos sujeitos, pode-se pensar que os indivíduos são alvos inertes do poder. A arqueogenealigia faz emergir o jogo das forças e coloca os sujeitos da história como imanentes aos próprios acontecimentos. Reside aqui a segunda grande contribuição de Foucault para a História: uma nova anatomia do poder. 


\section{(2) Nova anatomia do Poder.}

Os indivíduos sempre se encontram na posição de padecer e exercer o poder. São receptores e emissores. O poder funciona em rede. Não há dualismo em sua abordagem. Nem oposição entre realidade e aparência. 0 poder é relacional, provoca o consentimento pela livre adesão, uma vez que incorpora os indivíduos em suas malhas como numa rede, na qual todos, em algum sentido ou direção o exercem ao mesmo tempo em que sofrem seus efeitos.

Para estudarmos o poder, como exercício e não como coisa, Foucault propõe uma semiologia genealógica, capaz de atingir os fenômenos nas suas formas embrionárias e, a um só tempo, abordar os sintomas dos acontecimentos, entendidos não a partir de um estruturalismo que elenque acontecimentos, mas como uma abordagem que contemple os fenômenos a partir de sua singularidade, enfatizando a descontinuidade e as malhas mais finas da rede do poder. (FOUCAULT, 2003, pp. 5-6). Embora o poder seja mais perceptível na forma das instituições, como o tribunal, por exemplo, ele não existe fora das relações sociais. O Juiz só exerce poder por que há alguém que é considerado um perigo à sociedade. Todo um aparato repressivo é montado a fim de eliminar os indesejáveis, controlá-los e minimizar sua periculosidade.

$\mathrm{Na}$ concepção liberal o poder é algo como um "bem" que os indivíduos podem possuir. Está sujeito a contrato, posse e alienação. É uma noção contratualista fortemente ligada ao conceito de soberania, ou seja, à visão jurídica do poder. Na concepção marxista, por sua vez, o poder serve para manter as relações de produção e permanece com semelhante concepção de poder enquanto posse. Quem tem dinheiro, tem poder. Estas duas formas de entender o poder são aquelas que normalmente são ensinadas e reproduzidas. De modo muito particular no Ensino Básico, predominam os livros didáticos organizados cronologicamente e tendo por fio condutor as instituições e os grandes nomes da história política. Foucault propõe outra organização com relação ao poder. Ele se apropria da "hipótese Nietzsche", ou seja, de uma noção de poder concebido como luta. 
Evidente que a forma mais perceptível de poder é aquele que se faz sentir pela repressão, identificada como uma lei que diz não, ou, ao menos, como manutenção da ordem pelo uso da força. A proibição na concepção jurídica é, por sua vez, uma noção negativa. "Se o poder fosse somente repressivo, se não fizesse outra coisa a não ser dizer não você acredita que seria obedecido?" (FOUCAULT, 2003, p. 8). Esse questionamento de Foucault lança as bases da compreensão do poder como uma rede que atravessa 0 corpo social e produz adesão pelo convencimento.

É verdade que somos resistentes a esta nova proposta de pensamento acerca do poder. Isso também é fruto de uma construção. Desde o século XIII o verbo latino potere (poder, ser capaz de) sofreu influência do adjetivo potis (senhor, possuidor) e do verbo sum (ser, existir), passando a identificar-se com a capacidade de decidir, governar, ter voz de mando e autoridade. Somando-se a isso estão os totalitarismos de nossa história política recente que nos impregnaram da visão de um poder imbuído de arbitrariedade, violência e subjugação (PASSOS, 2008, p. 9-10). Assim, nossa percepção da noção de poder é centralizadora e negativa. O poder para Foucault só existe enquanto prática e ação relacional. Só existe em movimento, em relação. Apresenta uma visão positiva do poder, que não está vinculada a cargos ou instituições. Seu pensamento não fala de um poder "em si", fruto de uma posse ou relação contratual, mas de um poder que se estabelece entre as forças que estão em jogo. Foucault inverte a formulação de Carl von Clausewitz para falar do poder. Este diria que "a guerra não é mais que a continuação da política por outros meios". Para Foucault o poder é a guerra continuada por outros meios. Isso significa três coisas. Primeiro que as relações de poder são relações de força, não de autoridade. Segundo, que na aparente paz da sociedade civil reina veladamente a luta e o enfrentamento. Por fim, a inversão do aforismo de Clausewitz estabelece a noção de guerra contínua, de relações de forças diversas e conflituosas que perpassam a sociedade (FOUCAULT, 2005, p. 22-23). Esta guerra constante se estabelece não por armas e pelo uso da força, mas pelas diversas estratégias e táticas na qual 
todos os indivíduos, de alguma forma e em algum sentido, o sofrem e o exercem. Assim se refere Foucault ao poder:

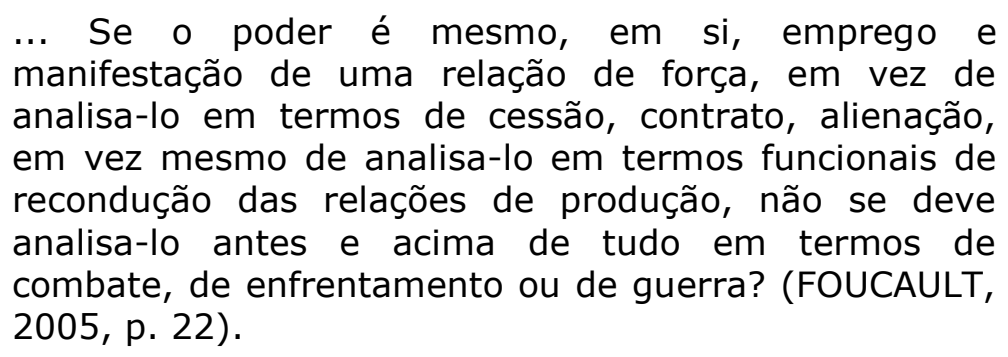

Foucault se interessa pelo "como" do poder. Deve-se, ao invés de buscar o poder político e sua hierarquia como centro do poder, esquadrinhar seus mecanismos e as múltiplas relações que constituem o corpo social. Para isso sugere algumas precauções de método: (1) apreender o poder em suas extremidades, tomando o poder em suas formas institucionais mais regionais e locais, sobretudo em seus instrumentos de intervenção material e regulação; (2) estudar o poder em suas práticas reais de regulação, onde se relaciona com seu objeto, sujeitando os corpos, dirigindo os gestos e regendo os comportamentos. Deve-se apreender sua instância material de sujeição. (3) Não tomar o poder como dominação de um indivíduo, ou grupo de indivíduos, sobre outros. Deve ser analisado como algo que circule, que exista em exercício, em ação e que funcione em cadeia. Os indivíduos jamais são alvos inertes, mas seus intermediários. (4) O poder circula na forma de rede e deve ser analisado ascendentemente, ou seja, a partir dos mecanismos infinitesimais, os quais possuem sua própria história. Examinar o modo como os fenômenos, as técnicas, os procedimentos de poder atuam, se mostram, se deslocam, são consentidos, modificam os indivíduos e produzem seus efeitos. (5) Compreender a relação saber/poder. O saber é uma forma de poder, um exercício de poder que tem suas técnicas de registro, métodos de observação, procedimentos de investigação e aparelhos de verificação. O poder põe em circulação determinados saberes, que se orientam para promover e/ou excluir. (FOUCAULT, 1999, p. 32-40). 
Em vez de dirigir a pesquisa e o ensino para o âmbito do edifício jurídico da soberania e da repressão, deve-se buscar as formas de sujeição. É preciso estudar o poder fora do modelo do Leviatã, fora do campo da soberania jurídica e analisar as leis, por exemplo, a partir das técnicas e práticas de dominação que buscam normalizar os indivíduos. Em Foucault, a noção de "repressão" é substituída por "normalização". A normalização descreve o funcionamento e a finalidade do poder que é regular a vida dos indivíduos e das populações. A própria escola, por exemplo, ao ser estudada deve ser vista dentro do contexto de sua criação. Isso pode parecer óbvio, mas, não é tão simples. Não basta falar de seus fundadores ou estabelecer uma cronologia do ensino a partir de suas transições paradigmáticas. Interessa o a priori histórico. O que motiva, por exemplo, a invenção da escola e do estudante na modernidade? Que forças e relações de poder se estruturaram para pensar a formação daqueles indivíduos? A partir desta nova anatomia do poder não basta identificar nomes, lugares e tempos. É preciso desnaturalizá-la, criticar sua construção e entender como foi possível sua emergência.

Assim, estudar a emergência de um objeto - conceito, prática, ideia ou valor - é proceder à análise histórica das condições de possibilidade dos discursos que instituíram e "alojam" tal objeto. Não se trata de onde ele veio, mas como/de que maneira e em que ponto ele surge (VEIGA-NETO, 2011, p. 61).

Não se trata, portanto, de fazer uma análise do Estado e suas instituições. O poder estatal é mais um poder em meio a tantos outros. Deve-se abolir definitivamente a ideia de um centro irradiador de poder que fosse capaz de coordenar, ou tecer sozinho, a malha social, com seus códigos e leis. O que interessa no método arqueogenealógico é o que motiva a lei, o que está por traz dela, são os conflitos que a produziram e as razões não ditas. Interessa também os seus efeitos de subjetivação. Que sujeito que se pretende construir? Aonde se quer chegar com isso? Quem ganha e quem perde? Ganha ou perde o quê? Para Foucault, o poder se exerce na relação em níveis variados e em pontos diferentes da rede social. Esta nova anatomia do poder aparece de forma astuciosa, como um jogo. 


\section{(3) A História Como Jogo: À Guisa de Conclusão. ${ }^{3}$}

A palavra jogo surge em muitos dos escritos de Michel Foucault como um modo de compreender o funcionamento da sociedade e das relações humanas. É uma figuração do mundo e a História em seus jogos múltiplos, inumeráveis, de naturezas diversas e de relações múltiplas. A História vista como jogo, como o resultado da ação dos homens, tem como pano de fundo e razão de ser das próprias práticas humanas, na maior parte das vezes, conflituosas.

Nas disputas da vida os homens estabelecem seus jogos: táticas e estratégias que são orientadas para a arte de viver, em muitos casos sobreviver. Em suas ações os homens disputam os espaços físicos e existenciais. Dominam outros homens pela força e pela palavra, pela imposição ou pelo simples convencimento. Nestas disputas o discurso encontra-se como instrumento eficaz de poder: ele inventa a realidade. A vida social inexiste sem o conflito, sem luta por representação da realidade. A cultura é um campo fértil de imposição de verdades. Os veículos de cultura e informação são instrumentos destes jogos de poder/saber, que buscam conformar os indivíduos a partir de suas estratégias de convencimento. Foucault pensou a História mediada pela ação humana, assim como um jogo, na qual estratégias e táticas movem a criatividade do agir e do reagir.

A História vista como jogo marca a noção de descontinuidade, pois, sua razão de ser não está na origem, nos sujeitos fundadores ou na teleologia. A História não tem um sentido dado a priori. "O que se encontra no começo histórico das coisas não é a identidade ainda preservada da origem - é a discórdia entre as coisas, é o disparate". (FOUCAULT, 2003, p. 18). Ou seja, é o esforço humano de hierarquização. Não existe uma racionalidade, nem uma finalidade histórica. O sentido da História é seu acontecer. Ela é feita nos seus lances, nas diversas jogadas que buscam normalizar e subjetivar.

3 Conferir o texto "A História em Jogo: a atuação de Michel Foucault no campo da Historiografia". (ALBUQUERQUE JR, 2007, pp. 165-182). 
A escrever a "História da Sexualidade" II e III Foucault preocupou-se com os jogos que buscam conformar os indivíduos, sujeitá-los moralmente. A invenção de identidades para os sujeitos tem uma importância política fundamental. Até bem pouco tempo havia os "comunistas". A invenção do comunista como indivíduo perverso, inimigo da moral, dos bons costumes e da sociedade justificava as intervenções de força, por mais que extrapolassem o desumano. Hoje muito se fala do "marginal". Esse indivíduo sem rosto, muitas vezes, é personificado no morador da comunidade pobre do Rio de Janeiro e demais aglomerados urbanos. A pobreza tem sido criminalizada em nome do bem estar social. Foucault ensina a desnaturalizar esses jogos de poder que inventam a realidade e sujeitam os indivíduos. Onde está a verdade nisso? No discurso. Desmonte esta construção, quebre as palavras, e você encontrará os jogos de poder em suas intencionalidades e motivações, em sua face nua e sem disfarces.

A História deve, portanto, ser vista como um saber perspectivo. Nós participamos da história que contamos. Entramos no jogo para escrever a História. Escrevemos sobre aquilo que ainda nos incomoda. A História é uma máquina produtora de verdades interessadas. O prazer do historiador não está na descoberta da verdade oculta, mas na desmontagem das verdades impostas, dos comportamentos exigidos e das conformidades dessacralizadas. "Não me diga para permanecer o mesmo". (FOUCAULT, 2007, p. 20). Essa frase de Foucault sobre si mesmo bem poderia ser atribuída à História e ao trabalho do historiador e do professor.

A história tem por função mostrar que aquilo que é nem sempre foi, isto é, que é sempre na confluência de encontros, acasos, ao longo de uma história frágil, precária, que se formaram as coisas que nos dão a impressão de serem as mais evidentes. Aquilo que a razão experimenta como sendo sua necessidade, ou aquilo que antes as diferentes formas de racionalidade dão como sendo necessária, podem ser historicizadas e mostradas as redes de contingência que as fizeram emergir... (FOUCAULT, 2006, p. 499).

Assim, o historiador deve estar atento não às causas dos fatos, mas aos elementos que se cruzam, suas motivações, desejos e encontros. É daí que surgem os acontecimentos. O trabalho do historiador é de 
desmontagem. Interessa mostrar as peças do jogo em sua dispersão. Isso permite insuflar nova vida aos relatos, (ALBUQUERQUE JR, 2007, pp. 153) desconfiando de tudo que nos chega como natural e verdadeiro. 0 professor, por sua vez, deve levar o educando a pensar a História no registro das diferenças (BURMESTER, 2005, p. 47), criando oportunidades para a valorização do diacronismo, da multiplicidade dos olhares e das existências.

Foucault propõe três novos usos para a História, novas maneiras de praticá-la, e ensiná-la, que realçam seu caráter político e subjetivo. O primeiro é o uso paródico ou irônico, que se opõe à História vista como reminiscência ou conhecimento. É uma história que dessacraliza a realidade e o que dizem que somos. O segundo é o dissociativo e destruidor da identidade, que se opõe à História vista como continuidade e tradição. Propõe um afastamento da continuidade, o dilaceramento dos modelos de identidade que se impõem do passado. Por fim, o uso sacrificial e destruidor da verdade, que se opõe à História conhecimento. Uma história que desconfie de todas as verdades que nos chegam prontas, que suspeite de todas as certezas que nos chegam sem questionamento. Deve buscar destronar os ídolos, inquietar o pensamento e nos libertar do peso do passado acrítico (ALBUQUERQUE JR, 2007, pp. 185). Só é possível pensar a História com Foucault se tivermos coragem de repensarmos a nós mesmos e nossa prática.

\section{Referências}

ALBUQUERQUE JR, D. M. de. História: a arte de inventar o passado. Ensaios de teoria da história. Bauru, SP: Edusc, 2007.

BARROS, J D'A. Teoria da História (Vol. 3): os paradigmas revolucionários. Petrópolis, RJ: Vozes, 2011.

BURK, P. História e Teoria Social. São Paulo: Editora Unesp, 2002. 
BURMESTER, A. M. O. Em defesa da sociedade. In RAGO, M.; ORLANDI, L. B. Lacerda; VEIGA-NETO (Org.). A. Imagens de Foucault e Deleuze: ressonâncias nietzschianas. 2 ed., Rio de Janeiro: DP\&A, 2005.

CASTRO, E. Vocabulário de Foucault: um percurso pelos seus temas, conceitos e autores. Belo Horizonte: Autêntica Editora, 2009.

CRUZ, M. B. A. O ensino da história no contexto das transições paradigmáticas da História e da Educação. In NIKITIUK, Sonia L. (Org.). Repensando o Ensino de História. 4 ed. , São Paulo: Cortez, 2001.

FOUCAULT, Mi. Segurança, Território, População. São Paulo: Martins Fontes, 2008.

2007.

A Arqueologia do saber. Rio de Janeiro: Forense Universitária,

. Estratégia, Poder-Saber. Ditos e Escritos (Vol. IV). Rio de Janeiro: Forense Universitaria, 2006.

2005.

A Verdade e as Formas Jurídicas. Rio de Janeiro: NAU Editora,

. A Ordem do Discurso. São Paulo: Edições Loyola, 2004.

. Microfísica do Poder. Rio de Janeiro: Edições Graal, 2003.

Em Defesa da Sociedade. São Paulo: Martins Fontes, 1999.

. Vigiar e Punir: nascimento da prisão. Petrópolis: Vozes, 1987.

PASSOS, I. C. F. Situando a analítica do poder em Michel Foucault. In PASSOS, Izabel C. F. (Org.). Poder, normalização e violência. Belo Horizonte: Autêntica Editora, 2008.

PEY, M. O.; BACCA, A. M.; SÁ, R. S. de. Nas Pegadas de Michel Foucault: apontamentos para a pesquisa de instituições. Rio de Janeiro: Achiamé, 2004.

RAGO, M. Foucault, História e Anarquismo. Rio de Janeiro: Achimé, 2004. TÉTART, P. Pequena história dos historiadores. Bauru-SP: EDUSC, 2000. VEIGA-NETO, A. Foucault e a Educação. 3 ed., Belo Horizonte: Autêntica Editora, 2011.

WITTGENSTEIN, Ludwig. Anotações sobre as cores. Lisboa: Edições Setenta, 1987. 